\title{
Inequalities in health: changes in RHAs in the past decade
}

\author{
R BALARAJAN, P YUEN, D MACHIN
}

Inequalities in health in Britain were highlighted by the Black report, ${ }^{\prime}$ and more recent data from the decennial supplement on occupational mortality, published by the Office of Population Censuses and Surveys, ${ }^{2}$ have been used to show that inequalities have widened over the past decade. ${ }^{3}$ Differences in inequalities are greater in Scotland and the north west of England than in the south east.

That inequalities in health should be reduced by the year 2000 is now promoted nationally and internationally through the health for all objective of the World Health Organisation. ${ }^{4}{ }^{5}$ If this is to become a reality in Britain the National Health Service, which has been vested with the objective of promoting the health of the nation, ${ }^{6}$ faces a major challenge.

In this study we have estimated the present inequalities and the shifts that have occurred over the past decade between the English regional health authorities for different causes of death. Our findings relate to all causes, ischaemic heart disease, and lung cancer.

\section{Methods}

Estimations of mortality by social class in England and Wales have been provided by the Registrar General's decennial supplement on occupational mortality. ${ }^{78}$ The approach of these studies has been to calculate death rates by relating social class at death registrations for a few years around each census with the number of persons enumerated in each class at the respective census. Social class is defined according to the Registrar General's classification and is based solely on the individual's employment..$^{10}$ The decennial supplements relating to the 1971 and 1981 censuses were used for this study ${ }^{82}$; the former covered deaths for the years 1970-2 and the latter for the years 1979, 1980, 1982, and 1983.

Biases in certain sections of the data render full social class mortality analysis less reliable in the $1979-83$ supplement. ${ }^{2}$ This has been attributed to an apparent improvement in the ability of the census to classify many individuals to more appropriate and specific occupations and thus often to different social classes. This improvement was not apparently shared in death registration data. This bias was thought principally to affect the estimated mortality in social class $\mathrm{V}$ (unskilled workers).

In this study the mortality of men aged 25-64 was examined by the different social class combinations. Standardised mortality ratios (SMRs) were first calculated for the usual social class groupings and the 14 English regional health authorities (fig 1) for the two calendar periods (1970-2 and 1979-83) using the 1979-83 age specific

\footnotetext{
Clinical Epidemiology and Public Health Research Unit, Robens Institute, University of Surrey, Guildford GU2 5XH

R BALARAJAN, MB, MFCM, director

$P$ YUEN, MSC, MIS, research fellow

D MACHIN, BSC, MSC, senior research fellow

Correspondence to: Dr Balarajan.
}

death rates ( 10 year age groups) as standard. This analysis suggested that the social classes could be regrouped into four relatively homogeneous categories: upper (I and II), III non-manual, III manual, and lower (IV and V). As the present regional health authority boundaries were created in 1974 they are compared with the corresponding former regional hospital board areas.

Improvement in mortality was defined for each cause of mortality as the percentage improvement between the two periods against the levels prevalent in 1970-2 and calculated separately for the four social class groups. Differentials were determined by calculating the difference in SMRs between the upper and lower social class groups separately for each period. Shifts are the differences of these differentials between the two periods.

\section{Results}

\section{ALL CAUSES}

The improvement in mortality from all causes between 1970-2 and 197983 showed a distinct social class gradient, being greatest in the upper social class $(19 \%)$ followed by social class III non-manual (17\%), social class III manual $(13 \%)$, and least in the lower social class $(6 \%)$. The differentials and the corresponding SMRs are shown in figure 1. For the upper social class the

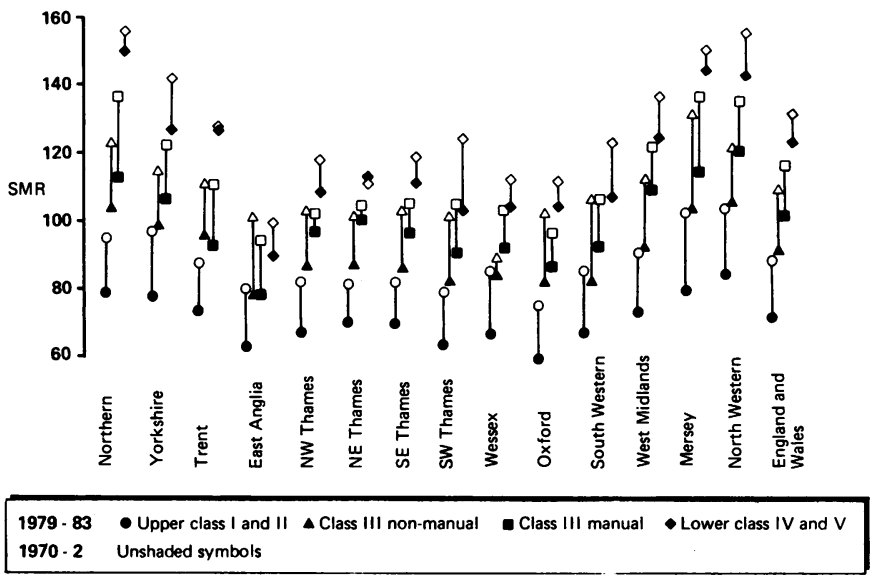

FIG 1-Mortality from all causes in men aged 25-64 between 1970-2 and 1979-83 by social class and regional health authority.

improvement was least in North East Thames, South East Thames, and Trent regional health authorities and greatest in Mersey and Wessex regional health authorities (fig 2A). The lower social class showed improvement in mortality levels in all regional health authorities except North East Thames (fig 2B). Other regions that showed little improvement were Trent, Northern, and Mersey. The largest improvement in percentage terms was seen in South West Thames (17\%) followed by South Western (13\%). North East Thames Regional Health Authority also showed the least improvement for class III manual. Inequalities in the 1979-83 period were greatest in Northern (71), Mersey (65), and North Western (59) and lowest 

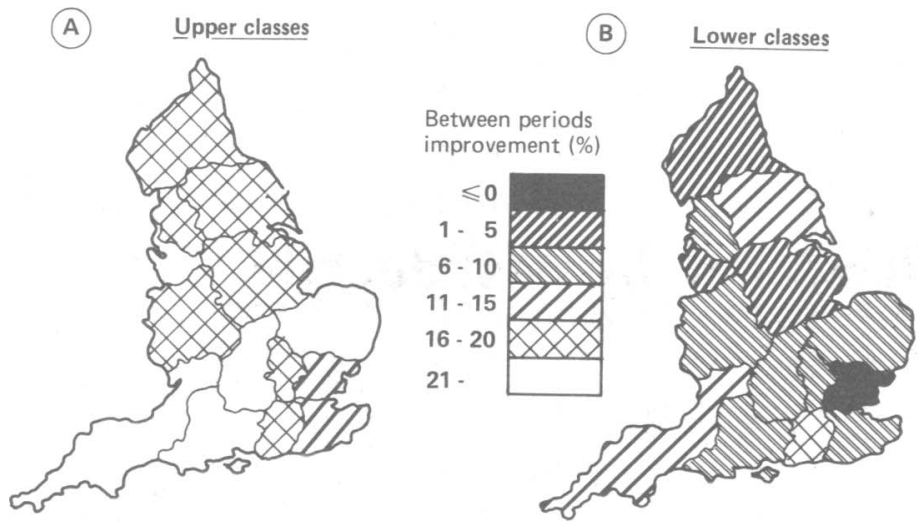

(C) Differentials 1979-83
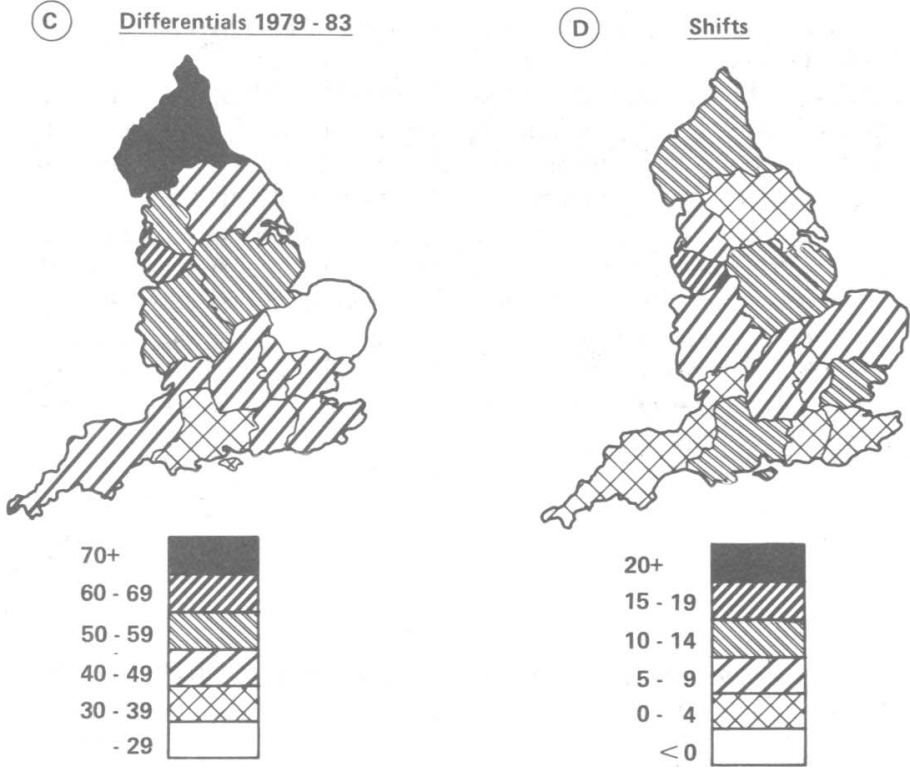

FIG 2-Changes in mortality from all causes in men aged 25-64 between 1970-2 and $1979-83$ by regional health authority.

in East Anglian (27) and Wessex (38) regional health authorities (fig 2C). The differences between the upper and the lower social classes widened in England and Wales over the past decade from a difference in SMR of 43 in 1970-2 to 52 in 1979-83. This widening in inequalities was highest in Mersey followed by Trent and North East Thames (fig 2D).

\section{ISCHAEMIC HEART DISEASE.}

In England and Wales ischaemic heart disease showed social class gradients with an SMR of 77 for the upper class and 115 for the lower class for the period 1979-83. The improvement after the 1970s was mostly in the upper class (14\%) followed by social class III non-manual (12\%). There was no appreciable change in mortality in class III manual but a worsening among the lower class by $6 \%$ over the period. The comparative higher mortality in class III among non-manual compared with manual workers in the 1970s had reversed in the 1980s. The earlier pattern, however, prevailed in Trent, East Anglian, and Oxford regional health authorities (fig 3).

Regional differences existed among the social classes, being least for the upper social class (62 in East Anglian to 100 in North Western) and greatest for the lower social class (82 in East Anglian to 140 in Northern). Mersey, Northern, and North Western regional health authorities showed high levels among all classes. Improvement in the upper social class was greatest in Mersey. In contrast the least improvement was in adjoining North Western followed by Trent and South East Thames (fig 4A). The lower social class showed increasing mortality in all regional health authorities except South Western and South West Thames, with Trent, North East Thames, and Mersey showing the greatest increases (fig 4B). The social class gradient between the upper and lower social classes was highest in Northern followed by Trent and Mersey and least in East Anglian and Wessex (fig 4C). The widening of these differentials over the decade was greatest in Mersey followed by Trent, North East Thames, and Northern (fig 4D).

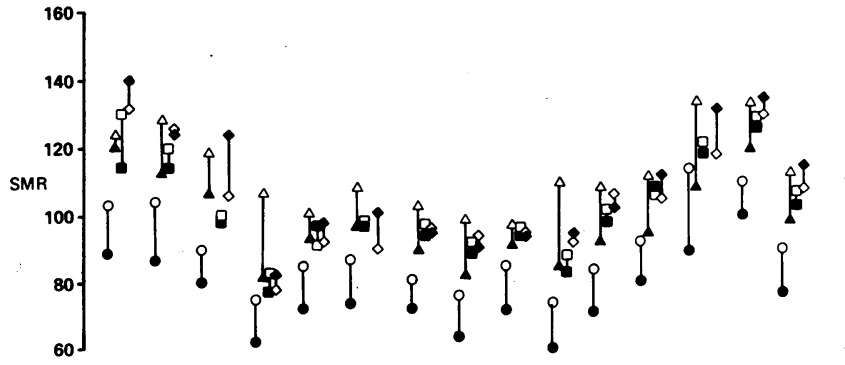

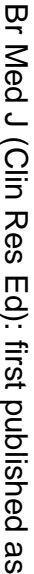

1979-83. Upper class I and II $\triangle$ Class III non-manual $\triangle$ Class III manual • Lower class IV and V
1970.2 . Unshaded symbols

FIG 3-Mortality from ischaemic heart disease in men aged 25-64 between 1970-2 and $1979-83$ by social class and regional health authority.
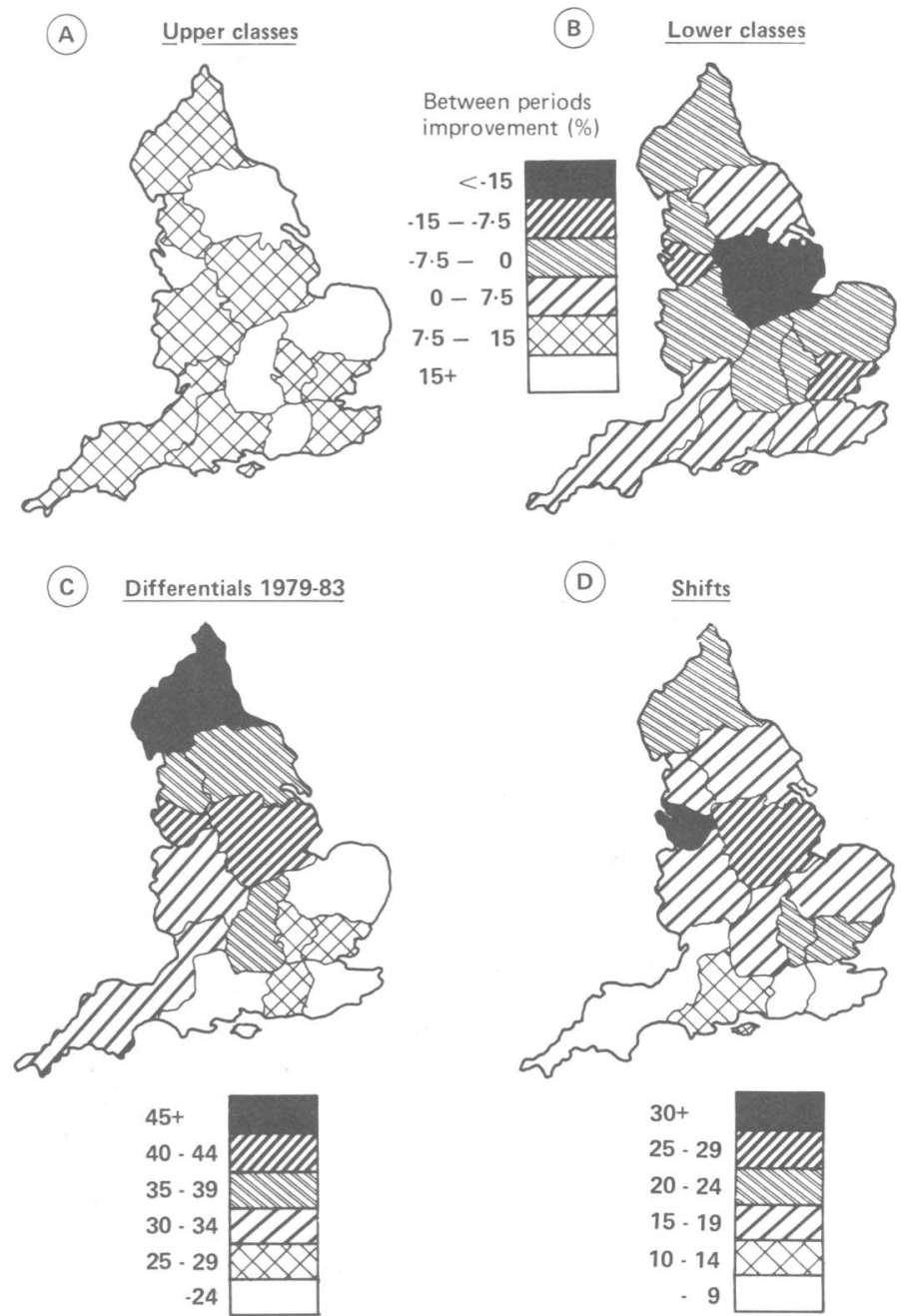

FIG 4 - Changes in mortality from ischaemic heart disease in men aged 25-64 between $1970-2$ and $1979-83$.

\section{LUNG CANCER}

The decline in the mortality from lung cancer showed a social class gradient with the upper social class greatest $(26 \%)$ and the lower social class least $(11 \%)$. The regional variations were less marked for the upper social class (SMR 46 in Wessex to 72 in North Western) than the other classes with the largest differences among the lower social class (SMR 100 in East $\stackrel{+}{?}$ 
Anglian to 184 in Mersey). South East Thames, South Western, North East Thames, Northern, and Yorkshire regional health authorities showed the least improvement for the upper social class. The lower social class showed improvement in most regional health authorities in the south east of England (fig 5B). The social class gradient between the upper and lower social classes was highest in Mersey (SMR difference of 123) followed by Northern (difference 113), and least in East Anglian (difference 47). Nationally the social class gradient widened over the study period (SMR difference of 74 in 1970-2 to 78 in 1979-83), contrasting with Thames and South Western regional health authorities, which showed a narrowing social class gradient (fig 5D).

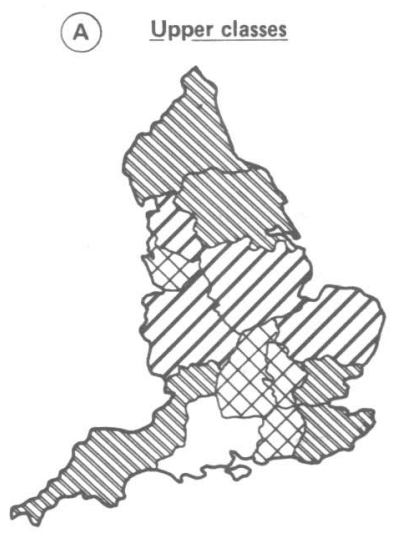

C Differentials $1979-83$

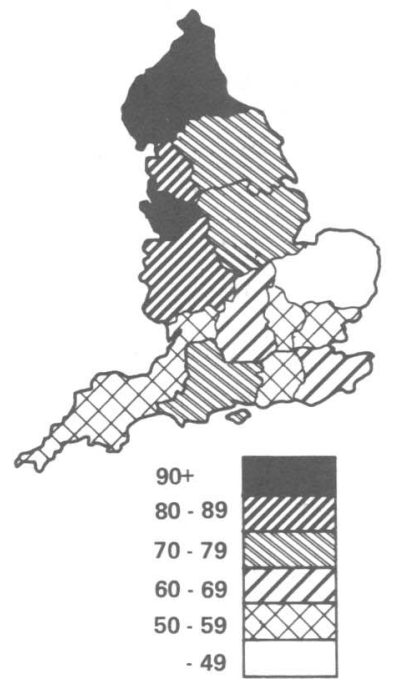

FIG 5-Changes in mortality from lung cance

\section{Discussion}

The decennial supplements on occupational mortality have traditionally provided the database for social class analysis over time. Biases resulting from the use of two separated sources of unlinked data (death registration and censuses) have been known to exist in the methods used in the decennial supplements since their inception. ${ }^{11}$ It was judged that this bias had worsened in the 1979-83 study, making full social class analysis unreliable. ${ }^{2}$ The data were therefore published without detailed commentary on the traditional social class groupings. This approach led to some controversy that official statistics had been suppressed. ${ }^{12-15}$ The data made available by the Office of Population Censuses and Surveys in the latest decennial supplement on occupational mortality are, however, more extensive and are adequate for researchers to analyse and interpret carefully their own findings on mortality related to social class. Previous papers based on this supplement have taken a cautious approach to classification by broadly grouping them into non-manual and manual classes.
We found that the social class groups I and II and IV and V were internally relatively homogeneous with respect to mortality from all causes, ischaemic heart disease, and lung cancer and we therefore regrouped them into upper and lower social class categories. In contrast III non-manual and III manual seemed to differ with respect to these same variables and so were kept distinct for our analysis. In general there is a gradient of increasing mortality from upper, III non-manual, III manual, and lower social class groups. Though for purposes of this study we think that the classification adopted is sufficiently robust, it may require adjustment in other studies depending on the particular hypotheses examined.

Our findings showed a differential improvement in all cause mortality nationally between the upper and lower social classes with improvement as high as $19 \%$ in the upper and only $6 \%$ in the lower with marked regional variations. One regional health authority (North East Thames), losing revenues through the Resource Allocation Working Party formula, showed increasing mortality among the lower social class. The differential between the upper and lower social class increased nationally between $1970-2$ and 197983 by $16 \%$. Again there were regional variations, with the largest difference in Mersey followed by North East Thames. North East Thames Regional Health Authority showed a lower improvement for all classes with the least improvement among the regions for three social class groups. Among its 15 districts North East Thames has five within Craig's lower socioeconomic clusters. ${ }^{16}$ The increasing mortality in the lower social class among North East Thames residents is of concern and should be carefully evaluated in the light of the problems known to face inner London. ${ }^{17}{ }^{18}$ The data available do not permit us to analyse inequalities in health in inner London.

There was little improvement in mortality among the lower social class for ischaemic heart disease in any region, being least in Trent, North East Thames, and Mersey. Though the gradient between the upper and lower social classes is higher in the north of the country the widening of the differentials after the 1970s was third greatest in North East Thames. The widening was greatest in Mersey, which is attributed to both an improvement in the upper class together with a decline in the lower class. For the causes of death studied regional differences in social class gradient were greater for lung cancer. The regions in the south east and south west of England, however, narrowed their gradients over the decade.

If these inequalities are to be reduced greater emphasis should be placed on health promotion and prevention of disease addressed differentially to the various risk groups. It is discouraging to see widening differentials in regions, such as North East Thames, which have previously ranked better, though it has to be emphasised that the inequalities are greater in the north and north west of England. It is too early to relate these findings to the present allocation process ${ }^{18}$ though the trends undoubtedly forewarn us of the possible long term effects on London of the present system which redistributes money away from the Thames regions in times of economic squeeze.

The widening inequalities and the differential shifts in the regions have social implications beyond the health service alone and these are undoubtedly important public health issues of today. Thus concerted efforts have to be made not only in health care but in other areas such as.housing, unemployment, and education if health for all by 2000 is to become a reality.

We should like to thank Dr Michael McDowall, Ms Sara Arber, and the South West Thames Regional Health Authority.

\section{References}

Black D, Morris JN, Smith C, Townsend P. Inequalities in health. Suffolk: Chaucer Press, 1982. (Black report.)

2 Office of Population Censuses and Surveys. Registrar general's decennial supplement on occupational mortality 1979-83. London: HMSO, 1986.

3 Marmot MG, McDowall ME. Mortality decline and widening social inequalities. Lancet 1986;ii:274-6.

4 World Health Organisation. Targets for health for all 2000. Copenhagen: WHO, 1985.

5 Faculty of Community Medicine. Health for all by the year 2000. Charter for action. London: Faculty of Community Medicine, 1986. 


\section{Future looks bleak for medical teachers, says MASC chairman}

The fact that clinical academic staff will receive their 1987 pay award at the same time as their National Health Service colleagues was due to the general election, according to the chairman of the Medical Academic Staff Committee, Dr Colin Smith. Reporting to the conference, he said that they had been used as shock troops in the past few years and he saw little prospect of the position improving. Two unprecedented events had taken place. One university-Bristol-had for a time said that it could not afford to pay the 1986 salary increase although the increase had been agreed. This year the Committee of Vice Chancellors and Principals (CVCP) had said that the universities could not afford to pay any increase and the committee threatened to withdraw from negotiations in the Clinical Academic Staff Salaries Committee (CASSC). Because of the imminent election the threats to the loss of parity with NHS staff and to the loss of the negotiating forum had disappeared when the Secretary of State for Education and Science had announced that an extra $£ 3.25$ million would be made available (6 June, p 1496).

Although the outcome this year had been satisfactory, Dr Smith believed that the future looked bleak. The universities had declared that without a reorganisation of the funding so that salary awards were carried forward to future years-that is, increasing the baseline funding-they would be unable to meet future pay awards whether the money for that year was forthcoming or not. So CASSC was determined to seek a meeting with the new secretary of state to pursue the problem of salary funding.

The BMA had questioned the universities' righ to withdraw unilaterally from CASSC, Dr Smith said, when so many other organisations were involved. It was essential for the committee to continue because of the items still unresolved. Some universities had failed to implement properly unit of medical time payments for junior staff; there were still problems about domiciliary payments; and clinical academic staff were unable to do private practice on the same basis as their whole time NHS colleagues.

Turning to the effects of the work of the Join Planning Advisory Committee, which is looking a the national targets for training posts taking into account the manpower plans of regional health authorities and their associated universities, D Smith reported that most regions had been sympathetic to the problems of universities and their staffing. He urged any representatives who were facing difficulties with regional joint planning advisory committees to contact the BMA. Debates were continuing on the final outcome of Hospital Medical Staffing: Achieving a Balance. A working party, chaired by the chief medical officer, was looking at the particular problems of academic medicine. This recognised, Dr Smith believed, that there needed to be flexibility in the time taken to do research and in the arrangements for moving between the NHS and academic medicine.

The conference of medical academic representatives (COMAR) met on 8 June with Professor J P Payne, professor of anaesthetics at the London Hospital Medical College, in the chair. The chairman of the Medical Academic Staff Committee, Dr Colin Smith, gave an account of the work of his committee during the past year and Professor Payne reported on clinical staff remuneration. The president elect of the BMA, Mr David Bolt, addressed the conference on the past, present, and future of the review body system. The chairman of the 1988 conference will be Dr J J Ferguson of the department of general practice at Edinburgh University, with Dr G M Mitchell, department of pharmacology, University of Wales College of Medicine, as his deputy.

The conference was told that there had been little change in the problems of medically qualified preclinical staff. The CVCP had been formally told of the BMA's policy to obtain negotiating rights. The committee had finally asked for the information on which the request was based-that is, the results of the ballot. Dr Smith forecast that with all the problems facing the universities the debate would be protracted. Though Dr Smith said that the decision to introduce two categories of nonclinical lecturer grade was a threat to preclinical staff, the conference did not support a motion opposing the decision. Professor Payne pointed out that it was part of a negotiated package, and $\mathrm{Dr}$ L $M$ Adams said that it introduced flexibility and could improve the recruitment of preclinical staff.

The funding of the universities was the key feature that clinical academic staff would have to face over the next few years, according to the chairman of MASC. Even the best funded universities were still facing a financial reduction in real terms. Funding problems affected staffing and the ability to maintain the research infrastructure. There was a misunderstanding in government as to how universities worked. The main feature of the
Croham report, which reviewed the working of the University Grants Committee, had been that the $\underline{\underline{w}}$ universities would contract to give educational service. Would universities, Dr Smith asked, have to contract to provide medical education at the lowest possible unit cost, to do research for the government, to take on so many overseas students, to provide services for the NHS as well as to teach? He foresaw that in future funds would be determined by what was provided, and there could be an impact on contracts of clinical academic staff.

Although there had been a reduction in clinical academic staff, the intake of medical students remained the same. So the teaching resources had to be spread more thinly or commitments dropped from the curriculum. Some universities, Dr Smith said, were close to bankruptcy if they kept the same facilities going. The only way forward was for clinical academic staff and the vice chancellors to indicate that the latter's dependence on academic staff to provide the future doctors could not be maintained without adequate resources. The conference should say loud and clear that if adequate funding was not made available there would be a serious crisis. "Once you have lost the infrastructure you will not retrieve it," Dr Smith declared.

\section{The conference...}

believed that parity of salary between NHS and clinical academic staff must be preserved.

resolved that the Clinical Academic Staff Salaries Committee (CASSC) should continue to consider salaries and salary related matters for clinical academic staff.

insisted on the preservation of CASSC as the negotiating forum for clinical academic staff and urged the Committee of Vice Chancellors and Principals to reconsider its threat to withdraw from the negotiations.

asked CASSC to find ways of ensuring that the costs of clinical academic salary payments were built into the universities' baseline funding for future years.

- said that the remuneration of clinical academic staff should come within the remit of the doctors' and dentists' review body.

supported the council's formal applica. tion for the recognition of the BMA as the sole negotiating body for medically qualified preclinical teachers.

deplored the continued reduction in university funding and called on the government to review its policy.

viewed with deep concern the reduction $D$ in numbers of medical academic staff and warned of the irretrievable detrimental effect $N$ on medical education.

Talking Point-continued from page 1563.

\footnotetext{
6 Ministry of Health and Department of Health for Scotland. A national health service. London HMSO, 1944. (Cmnd 6502.)

Registrar General. Supplement, England and Wales, 1921. Part II occupational monality, fertility and infant monality. London: HMSO, 1927.

8 Office of Population Censuses and Surveys. Registrar general's decennial supplement on occupational mortality 1970-72. London: HMSO, 1978.

mortality 1970-72. London: HMSO, 1978.
Office of Population Censuses and Surveys. Classification of occupation. London: HMSO, 1980.

10 Leete R, Fox AJ. Registrar general's social classes: origins and uses. Population trends 8: summer 1-7. London: HMSO, 1977.

11 McDowall ME. William Farr and the study of occupational mortality. Population trends 31: sprin 12-14. London: HMSO, 1983
}

12 Taylor R. Tories' way with figures. Observer 1986 August 3:5.
13 Anonymous. Lies, damned lies, and suppressed statistics [Editorial]. $\mathrm{Br} \mathrm{Med} \mathcal{F}$ 1986;293:349-50. 14 Alderson MR. Lies, damned lies, and suppressed statistics. Br Med f 1986;293:503.

15 Anonymous. The occupational mortality supplement: why the fuss [Editorial]. Lancet 1986;ii: 610-11.

16 Office of Population Censuses and Surveys. Craig J. A 1981 socioeconomic classification of local and health authorities of Great Britain. Studies on medical and population subjects No 48. London: HMSO, 1985 .

17 London Health Planning Consortium Study Group on Primary Health Care in Inner London Report. London: HMSO, 1981. (Acheson report.)

18 Balarajan R. On the state of health in inner London. Br Med $\mathcal{F} 1986 ; 292: 911-14$

(Accepted 1 May 1987)

Published by the Proprietors, THE BRITISH MEDICAL ASSOCIATION, Tavistock Square, London WC1H 9JR, and printed in Great Britain by Pulman Web Offset Limited. Typesetting by Bedford Typesetters Limited, Bedford. Registered as a Newspaper. 